\title{
Practice of Community and Clinical Pharmacy- Need for the society
}

\author{
Anantha Naik Nagappa ${ }^{1 *}$, Vinuth Chikkamath ${ }^{2}$, Vaishnavi Naik ${ }^{2}$, Santosh Uttangi², Jeena $\mathbf{M ~ J a c o b}^{3}$ and Nimmy $\mathbf{P}$ \\ George $^{3}$ \\ ${ }^{1}$ Amity Institute of Pharmacy, Amity University, India
}

${ }^{2}$ Department of Pharmacy Practice, SCS College of Pharmacy, India

3Department of Pharmacy Practice, Nargund College of Pharmacy, India

Submission: December 17, 2018; Published: January 28, 2019

*Corresponding author: Anantha Naik Nagappa, Amity Institute of Pharmacy, Amity University of Madhya Pradesh, Gwalior, 474005, India

Keywords: Clinical pharmacy; Retail pharmacists; Disease prevention; Inpatient pharmacy; Satellite pharmacy; Oncology pharmacy

\section{Introduction}

The definition of "retail" is the sale of goods to ultimate consumers. "Clinical pharmacy" is a health science discipline in which clinical pharmacists provide patient care that optimizes medication therapy and promotes health and disease prevention. By these definitions, the retailer is a purveyor of a product, and the clinical pharmacist is a provider of a service. Competing metrics are in play--selling more of a good versus providing more of a service. If one is evaluated on the output of prescriptions in a specified time period, the patient care component becomes secondary to the focus of the pharmacist--not an ideal situation when pharmacists are trained to be care providers.

Retail pharmacists have little direct involvement with patients, other than filling prescriptions and advising on potential side effects or complications. Clinical pharmacists require a more advanced and patient-oriented skill set. While retail pharmacists must be aware of potential adverse effects or drug interactions, clinical pharmacists must recognize the symptoms on sight. Physicians consult with clinical pharmacists on medications and dosages, exactly as they'd consult with other doctors with specialized expertise. Clinical pharmacists often compound medications to order, and typically need better compounding skills than their retail peers.

Pharmacists are known to service in the hospital as Clinical Pharmacist and Hospital Pharmacist. The Clinical Pharmacist provides the service to patients and to the fellow health care professionals like Doctors and Nurses in the matter of patient safety and efficacy of the treatment. They work in hand and hand with Doctors and Nurses in updating the patient profile in the mattes of drugs and treatments. The Hospital Pharmacist are known to engage themselves in the logistics of medicines, required in the hospitals they are supervise the inpatient pharmacy, satellite pharmacy, and oncology pharmacy etc. They are also engaging in making customized formulations for a patient along with extemporaneous medicines. They also engage in the manufacture of bulk formulations required for the hospitals. They also engage in the manufacture of IV fluids and ointments, and other simple formulations which are used for consumptions in the hospitals.

Another important role of a Pharmacist is in the area of Community and Ambulatory Pharmacy. Community and Ambulatory Pharmacy have a unique nature of providing prescription medicines and other day to day OTC medicines to the patients and health consumers they are also called as Retail Pharmacist, Chemist and Druggist and Apothecaries. Their practice is entirely different from clinical and hospital, in fact the community pharmacist very dominant in most of the developed and developing countries. They are hardcore entrepreneur who invest their money and engage themselves in the service of outpatients the community pharmacist. The competitive market working with Stakeholders, Doctors, Nurses and Regulatory authorities and Pharmaceutical industries. The Community Pharmacist full engagement involve in the multi task like developing the business having lesion with Doctors, Nurses on whom he gets prescriptions.

The prescriptions are the legal document which to address the pharmacists to provide the unique medicines to the patients. The medicines are regulated with various rules and regulations and are subject to inspections by drug regulatory authorities to come, inspect and checks for various deviations in the business protocol. The retail pharmacist is bound by rules and regulations and must have a valid license issued by the Drugs Control Department for conduct of dispensing of drugs as per the 
prescriptions. They are responsible for providing appropriate environment conditions in which the formulations do not get deteriorated during the shelf life of the pharmacy. All the drug formulations have a date of expiry and it is a mandatory for the pharmacist to dispense the drug against with a validity date of expiry. Some pharmacist dispenses expired medicines they are liable for the punishment under the Drugs and Cosmetics act. The Community Pharmacist has their own code of ethics which emphasizes on the commitment of the pharmacist for the benefit of the pharmacist. The retail pharmacist supposes to check the prescription and make a quick survey of active pharmaceutical ingredient for any duplication of either therapeutic activity or over dosage. Checking the dose of the patient is an important activity, checking for the adverse drug reactions, drug allergies are also important procedure while dispensing the prescription. The retail Pharmacist should also have a dialogue with the patient and identify the areas of patient counseling required by the patient. They also should make an auxiliary label, explaining the patients how the drugs are like to impact or influence on overall health and the alertness. For example, some drugs are to be known to act on alertness of the patient they are ready to drowsiness in such circumstance's pharmacist has to give proper instructions to the patients.

In developed and developing countries the Retail Pharmacist in abroad like North America, Japan, New Zealand and Australia are highly respected by the Doctors and fellow professionals. Pharmacists also dedicate themselves to providing service to the public. They are highly professional community for the welfare of patient and health consumers. All the modern drugs carry a risk of adverse drug reactions, and a matter concern needs to be used after the theoretical estimate of risk versus benefits. If the benefits over the risk of the drugs needs to be used.

The allopathic drugs are known for the magic quick relief to the patient and make use of the allopathic medicines. Allopathic medicines carry a tag of systematic medicine, as they are developed based on scientific evaluations. Despite of these things they are very harmful, causing the considerable morbidity and mortality. The awareness of the public harmful effects of the drug is very high in the developed countries, the patients and health consumers depend upon the retails and the consumers are to advise of the pharmacist, how to protect themselves by the harmful effects of the drugs. The pharmacists are rewarded either by the government of Australia, New Zealand, and United States of America. Government is very keen to control the ill effects of the drugs by its widespread promotion and sales of the prescription medicines to the patient and health consumers, as the sole source of the income on the volume of income to the margin after sales of the income. The market is the product centric, all the stakeholders are engaged in pushing more and more drugs and making patients to believe one can achieve the $100 \%$ health this kind of tendency are very much harmful for the health of the public and health consumers as the side effects of the Nephrotoxicity, Cardiotoxicity are going to manifest after the several years of use of indiscriminate use of medicines. Unfortunately, are serious ill effects of the drug are never counted and reported. The Government also seems to not be serious about this issue as Pharma industries successfully convinces the Government by hook or crook clever advocacy. For example, the banning of the irrational Fixed Dose Combinations (FDC) by the Government revoked by the Judiciary giving the reason for the lack of evidence caused by the drugs. All these drugs are banned in the developed countries. The ethics and norms are trade is totally absent if visiting a medical shop where the people are exchanging the prescription medicines and narcotic medicines for money without care and concern for the people who buy this medicine. This has tarnished the image of pharmacy profession and a pharmacist is never looked with respect as they are projected mainly as traders rather than a healthcare profession. Due to poor regulation of the existing laws to provide the adequate protection to the public and people is a like a mirage in the desert [1-6].

\section{Essential Functions of Retail Pharmacist}

a) Reviews prescriptions issued by the Physician, or other authorized prescriber to assure accuracy, appropriateness of medication, and determine formulas and ingredients needed.

b) Directs pharmacy workers engaged in mixing, packaging, and labeling pharmaceuticals.

c) Answers questions and provides information to pharmacy customers on drug interactions, side effects, dosage and storage of pharmaceuticals.

d) Maintains established procedures concerning quality assurance, security of controlled substances, and disposal of drugs designated as hazardous waste.

e) Enters data such as patient name, prescribed medication and cost, to maintain pharmacy files, charge system, and inventory.

f) Assays medications to determine identity, purity, and strength.

g) Instructs interns and other medical personnel on matters pertaining to the pharmacy.

h) Communicates with and treats company's customers of various ages.

i) Participates in traditional and e-learning programs.

j) Works effectively with other company employees, managers, and departments.

k) Comply with all State and Federal Laws and Regulations.

l) Performs all job functions with Company Mission, Vision, and Goal Statements in mind.

\section{Essential Functions of Clinical Pharmacist}

a) Clinical pharmacists conduct a complete patient interview on medical history, social and family history, and 
history of allergy, use of OTC drugs, dietary supplements and alternative systems of medicine.

b) Clinical pharmacists perform review of drug therapy which helps to recognize and utilize relevant clinical and lab data to identify and resolve drug related problems such as duplication of therapy, drug-drug and drug-food interactions, contraindications, inappropriate dosage in terms of frequency \& strength, lack of basic lab monitoring requirements, potential ADRs, inappropriate drug selection, drug therapy without indication or no drug order for an indication, non-adherence to medications and availability of cost effective alternatives. c) They can assist in therapeutic decision making and the preparation of guidelines for antibiotic usage by assessing cost effectiveness.

d) Provision of unbiased, up-to-date information on any aspect of drug use is another major responsibility of a clinical Pharmacist.

e) They are capable of providing information on strength, availability of drug formulations, brand and cost.

f) They provide information regarding dosing of drugs in patients with renal or hepatic impairment function.

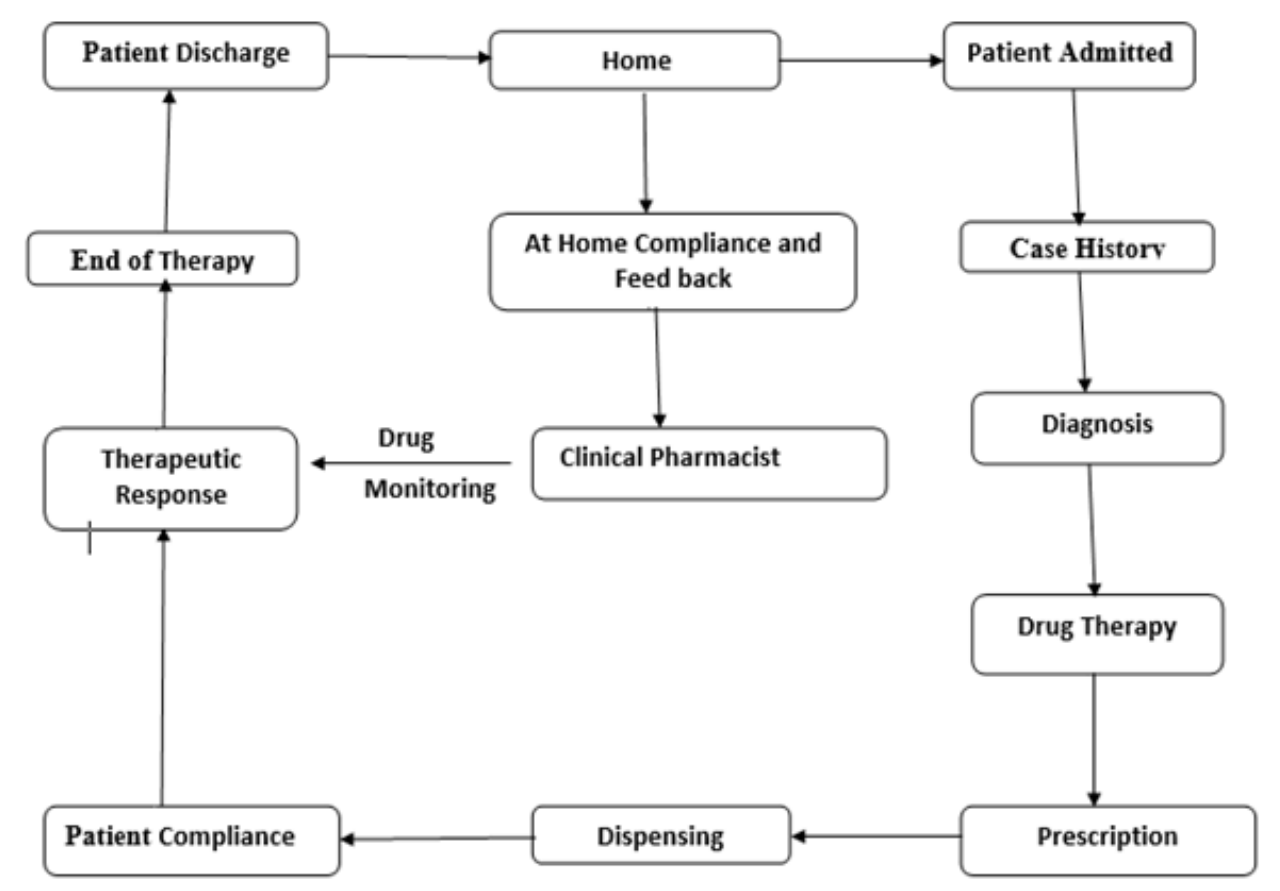

Figure 1: A Schematic representation depicting the scope of a clinical pharmacist in a treatment process.

g) Since a clinical pharmacist have thorough knowledge about the drugs they can easily identify and notify as lookalike and sound alike drugs.

h) They can actively participate in therapeutic drug monitoring, medical camps and patient awareness programs on medication usage.

i) Therapeutic Drug Monitoring is an important part of the Clinical Pharmacists activity to monitor the patient.

j) Clinical pharmacists ensure that reconstitution, dilution, stability, storage, compatibility and administration of drugs are to be carried out appropriately.

k) They have an active participation in physician rounds in all the departments of a hospital.

l) Clinical pharmacists in pediatrics and neonatology can help in dose calculation and dosage form modification (Figure 1 \& 2) (Table 1)..

Table1: Major Players in Pharma Retail Chain in India.

\begin{tabular}{|c|c|}
\hline Name of the Chain & Outlets \\
\hline Apollo Pharmacies & 340 \\
\hline Medicine Shoppe & 100 \\
\hline Dial for Health & 105 \\
\hline 98.4 & 15 \\
\hline Pill \& Powder & 12 \\
\hline Medicine Bazar & 10 \\
\hline Life Spring & 7 \\
\hline
\end{tabular}

\section{Conclusion}

There is an utmost need for the Government to investigate the current scenario of Retail Pharmacist practice in the country. 
The Retail Pharmacist should change their image from traders to profession engaging in the patient safety. International patient solidarity day emphasizes on safe medicine practices in order to protect the human life and health. The paradigm shift from product centric to patient centric health care is becoming at most necessary the health of the public dwindled due to irrational use of medicines.

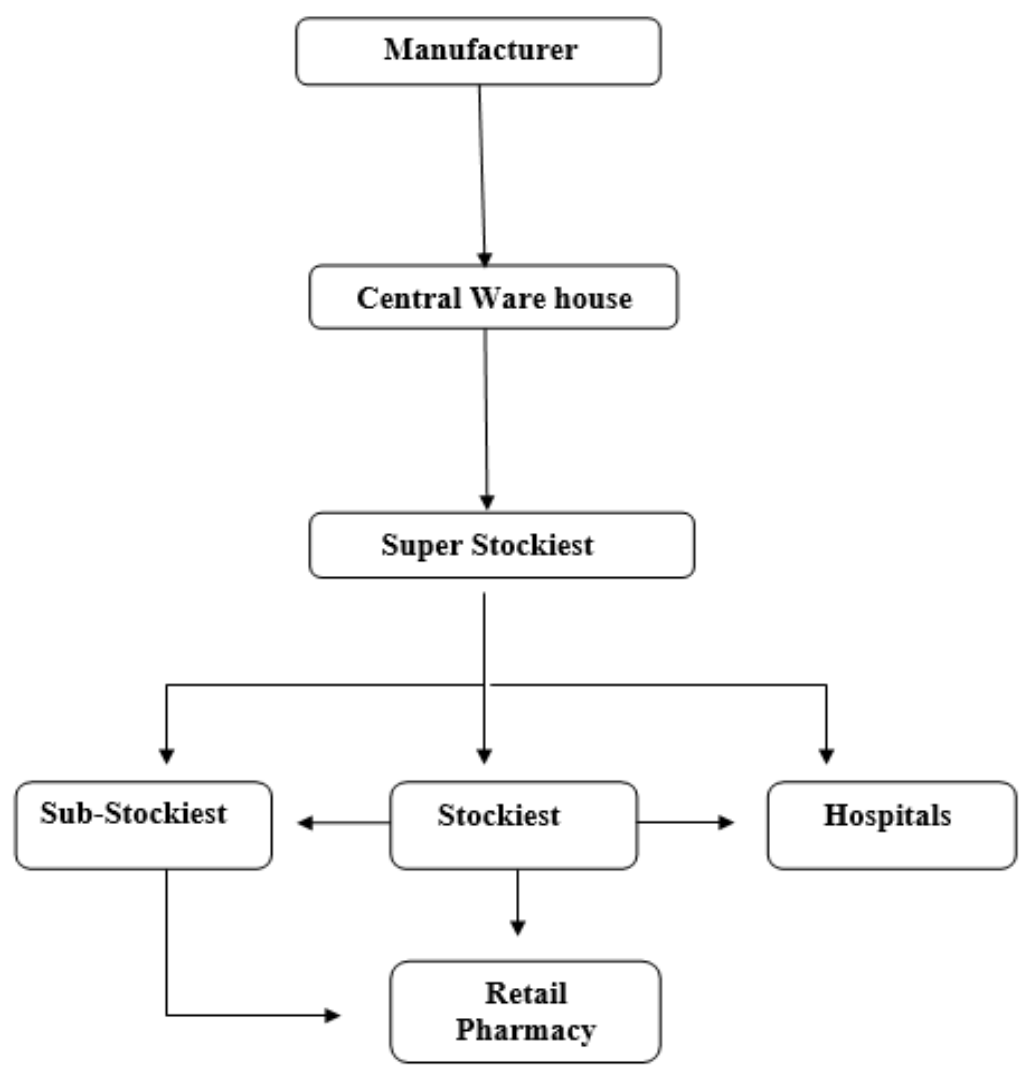

Figure 2: A Schematic representation depicting the scope of a clinical pharmacist in a treatment process.

\section{References}

1. Maureen S (2004) The expanding role of dental oncology in head and neck surgery. Surg Oncol Clin N Am 13(1): 37-46.

2. Kanatas AN, Rogers SN (2010) A systematic review of patient self-completed questionnaires suitable for oral and maxillofacial surgery. Br J Oral Maxillofac Surg 48(8): 579-590.

3. Fialka Moser V, Crevenna R, Korpan M, Quittan M (2003) Cancer rehabilitation: particularly with aspects on physical impairments. J Rehabil Med 35(4): 153-162.

4. Keyf F (2001) Obturator prostheses for hemimaxillectomy patients. J Oral Rehabil 28(9): 821-829.

5. McGregor IA, McGregor FM (1986) Cancer of the face and mouth: pathology and management for surgeons. Churchill Livingstone, London, United Kingdom.

6. Rodrigues SJ, Saldanha S (2011) Prosthetic rehabilitation of a patient after partial maxillectomy: A clinical report. Contemp Clin Dent 2(4): 355-358.
7. Goiato MC, Pesqueira AA, Ramos da Silva C, Gennari Filho H, Micheline Dos Santos D (2009) Patient satisfaction with maxillofacial prosthesis. Literature review. J Plast Reconstr Aesthet Surg 62(2): 175-180.

8. Beumer J, Curtis TA, Marunick MT (1996) Maxillofacial rehabilitation: prosthodontic and surgical considerations. In: Beumer J, Curtis TA, Marunick MT (Eds.), ( (st $^{\text {st }}$ dn), Ishiyaku Euroamerica Inc, USA.

9. Daniel AY, Vinod B (2015) Prosthetic rehabilitation of the dentate maxillectomy patient from a delayed surgical to an interim obturator: A clinical case report. CHRISMED Journal of Health and Research 2(1): 68.

10. Kanazawa T, Yoshida H, Furuya Y, Shimodaira K (2000) Sectional prosthesis with hollow obturator portion made of thin silicone layer over resin frame. J Oral Rehabil 27(9): 760-764.

11. Kornblith AB, Zlotolow IM, Gooen J, Huryn JM, Lerner T, et al. (1996) Quality of life of maxillectomy patients using an obturator prosthesis. Head Neck 18(4): 323-334. 
Your next submission with Juniper Publishers will reach you the below assets

- Quality Editorial service

- Swift Peer Review

- Reprints availability

- E-prints Service

- Manuscript Podcast for convenient understanding

- Global attainment for your research

- Manuscript accessibility in different formats

( Pdf, E-pub, Full Text, Audio)

- Unceasing customer service

Track the below URL for one-step submission https://juniperpublishers.com/online-submission.php 